\title{
DEGRADABILIDADE DO CAPIM-ELEFANTE EM DIFERENTES ESTÁGIOS DE MATURIDADE AVALIADA PELO MÉTODO IN VITROIGÁS
}

\author{
Fábio Prudêncio de Campos ${ }^{1 *}$; Dante Pazzanese Duarte Lanna²; Max Lázaro Vieira Bose; \\ Celso Boin²; Patrícia Sarmento ${ }^{1}$ \\ ${ }^{1}$ Pós-Graduando em Zootecnia/Produção Animal - UNESP/FCAV, Via de Acesso Prof. Paulo Donato Castellani, s/n \\ CEP: 14884-900 - Jaboticabal, SP. \\ ${ }^{2}$ Depto. de Produção Animal - USP/ESALQ, C.P. 9 - CEP: 13418-900 - Piracicaba, SP. \\ *Autor correspondente <fpcampos99@yahoo.com>
}

\begin{abstract}
RESUMO: O capim-elefante (Pennisetum purpureum Schum.) é uma gramínea tropical de elevada capacidade de acumulação de matéria seca, mas seu valor nutritivo é acentuadamente influenciado pela maturidade. Considerando a natureza intrínseca da parede celular nas diferentes partes da planta, o conhecimento de suas taxas e extensões de degradação permite a determinação de qual componente e qual estágio de maturidade que afeta sua digestão. Portanto, o objetivo deste trabalho foi avaliar a degradabilidade da matéria seca (MS) do capim-elefante cv. Napier, pelo método in vitro/gás, com cortes de 45 a 105 dias a intervalos de 10 dias entre os cortes. Notou-se decréscimo na degradabilidade das frações do capim-elefante com o avanço do estágio de maturidade. Os coeficientes de regressão da degradabilidade da MS estimados pelo resíduo remanescente da digestão para folhas e hastes foram 0,51 e 0,89 , respectivamente. Para degradabilidade da fibra em detergente neutro (FDN) os coeficientes de regressão para folhas e hastes foram 0,82 e 0,92, respectivamente. Na produção total de gás os coeficientes de regressão para folhas foi de 0,56 e 0,90 para hastes. Em geral, a haste do capim-elefante, com o avanço da maturidade vegetativa, apresentou maior influência no decréscimo da degradabilidade da MS e da FDN que as folhas. O avanço no estágio de maturidade do capim-elefante afeta diretamente a degradabilidade das hastes e das folhas. Isto é mais acentuado para hastes devido a elevada lignificação da parede celular.
\end{abstract}

Palavras-chave: FDN, folhas, forragem, hastes, matéria seca

\section{ELEPHANTGRASS DEGRADABILITY AT DIFFERENT MATURITY STAGES EVALUATED BY THE IN VITRO/GAS TECHNIQUE}

\begin{abstract}
Elephantgrass (Pennisetum purpureum Schum.) is a tropical grass of high dry matter accumulation capacity, but its nutritive value is strongly influenced by its maturity. Considering the cellular wall intrinsic nature of different parts of the plant, the knowledge of its rates and degradation extent allow the determination of which component and which maturity stage affects its digestion. Therefore, the objective of this trial was to evaluate the elephantgrass CV Napier dry matter (DM) degradability by the in vitro/gas technique, with cuts from 45 to 105 days, with intervals of 10 days between cuts. A decrease was noticed in the elephantgrass fraction degradability with the stage maturity progress. The DM degradability regression coefficients estimated of the digestion remaining residue for leaves and stems were 0.51 and 0.89 , respectively. For leaves and stems fiber degradability in neutral detergent (NDF) the regression coefficients were 0.82 and 0.92 , respectively. For the total gas production the regression coefficient for leaves was 0.56 and for stems 0.90 . In general, the elephantgrass stems, in relation to the progress of vegetative maturity, presented larger influence on the decrease of the DM and NDF degradability than the leaves. The progress in the elephantgrass maturity stage affects directly the stem and leave degradabilities. This is more accentuated for stems due to the more intense cellular wall lignification.
\end{abstract}

Key words: NDF, leaves, forage, stems, dry matter

\section{INTRODUÇÃO}

Vários são os trabalhos e técnicas utilizadas para se avaliar a qualidade das forragens para ruminantes. Uma metodologia que vem sendo utilizada é a de monitoramento computadorizado de digestão in vitro (Pell \& Schofield, 1993), uma técnica utilizada para obtenção das estimativas do tempo de colonização microbiana (lag-time), das taxas e da extensão da degradação da matéria seca das frações fibrosas e não fibrosas das forragens, pela curva da produção de gás oriunda da digestão microbiana, e a degradabilidade da matéria seca, pelo resíduo remanescente da digestão, após as 48 horas de incubação de amostras. Campos et al. (2000 b) relataram em seus trabalhos que a produção de gás é uma técnica nãoinvasiva, que visa a diminuição da utilização de animais canulados, em experimentos. Além disso, é uma técnica capaz de medir eficientemente a qualidade dos volumosos 
analisados, principalmente quando há necessidade de obter informações sobre a contribuição dos carboidratos solúveis e os prontamente disponíveis, como o amido.

$\mathrm{O}$ avanço da maturidade dos tecidos vegetais de plantas forrageiras e a conseqüente redução na digestibilidade da matéria seca são fenômenos intimamente associados. Esta redução, observada mais intensamente em gramíneas tropicais, interfere decisivamente na utilização dessas como alimento para ruminantes. Deschamps (1999) relatou que no avanço da maturidade fisiológica, as plantas forrageiras crescem acumulando maior quantidade de matéria seca e são acompanhadas pelo espessamento e lignificação da parede celular, ganhando assim altura pelo alongamento do caule e das folhas. Menciona também que os incrementos na deposição de lignina e as reduções nos teores de proteína bruta parecem ser as principais alterações químicas observadas na composição da matéria seca.

O capim-elefante é uma gramínea tropical de via fotossintética $\mathrm{C}_{4}$, o que the confere elevada capacidade de assimilação de energia solar e, portanto, maior acumulação de matéria seca. Essa rápida acumulação de MS aliada à maturidade do capim afeta acentuadamente seu valor nutritivo. Com esse padrão de crescimento, o capim-elefante apresenta menor flexibilidade quanto ao manejo, uma vez que pequenos atrasos no período de pastejo provocam desempenhos limitados por parte dos animais (Balsalobre, 1996). A razão para isto está no metabolismo acelerado da planta que gera modificações na estrutura e na composição da parede celular, comprometendo a digestibilidade do material (Deschamps, 1999). Apesar dos efeitos mencionados o capim-elefante ainda é uma forrageira que se adapta muito bem às condições edafoclimáticas encontradas nas regiões tropicais, pois produz alta quantidade de matéria seca, sendo, portanto, uma das forrageiras importantes para a alimentação de bovinos leiteiros e de corte.

À medida que a idade fisiológica da planta avança aumentam as porcentagens de hemicelulose, celulose e lignina, reduzindo assim a porcentagem do conteúdo celular, que tem de 98 a $100 \%$ de digestibilidade. As concentrações de proteína, lipídios e minerais tendem a se reduzir, principalmente após o florescimento.

A utilização de uma forragem na alimentação de bovinos depende da interação entre a planta, os microrganismos ruminais e o trato gastrointestinal do animal. Essa interação afeta diretamente a digestibilidade da parede celular, interferindo no consumo de MS e na produção de leite (Thiago \& Gill, 1990). Portanto, do ponto de vista da fisiologia digestiva dos ruminantes, a digestão dos alimentos depende, principalmente, da associação entre partículas de alimento e dos microrganismos ruminais presentes no processo digestivo (Chesson, 1993). A fibra indigestível se acumula no trato digestivo do animal, consequentemente reduzindo o espaço ruminal e o consumo de MS (Thiago \& Gill, 1990).
O consumo de forragem está relacionado com a taxa de passagem do alimento no rúmen, que por sua vez depende da velocidade de degradação e do tamanho de partícula do material avaliado (Ulyatt et al., 1986). A existência do tamanho crítico de partículas na passagem pelo orifício retículo-omasal sugere que a taxa de redução dessas partículas seja o fator dominante que regula a saída do material do rúmen. Isso explica o menor consumo de hastes comparado ao das folhas, já que estas possuem menor resistência à degradação que as hastes (Laredo \& Minson, 1973). Foi relatado por Galyean \& Goetsch (1993) que o consumo somente de folhas é maior que haste, devido as características das folhas e das hastes possuírem diferentes tempos de retenção ruminal, resultando em modificações na ingestão de alimento. Assim folhas passam mais rapidamente no rúmen que hastes.

Decréscimo na ingestão de alimentos com o aumento da maturidade é provavelmente uma função das características químicas e físicas das forragens. As químicas são atribuídas à palatabilidade, compostos tóxicos secundários e demanda de nutrientes. As características físicas incluem fatores que afetam a digestão e o fluxo da digestão Galyean \& Goetsch (1993). As barreiras físicas ditadas pelo arranjo das células ao longo do tecido ou das barreiras químicas decorrentes da parede celular são determinantes no processo digestivo de ruminantes (Deschamps, 2001).

Considerando a natureza intrínseca da parede celular nas diferentes partes da planta, o conhecimento de suas taxas e extensões de degradação permitem determinar qual componente e qual estágio de maturidade da planta mais afeta a digestão. Portanto, o objetivo deste trabalho foi avaliar a degradabilidade da MS, o tempo de colonização (lag-time), as taxas e a extensão da degradação do capim-elefante cv. Napier, pelo método in vitro/gás, nos diferentes estágios de maturidade do vegetal.

\section{MATERIAL E MÉTODOS}

O experimento foi realizado na USP/ESALQ, localizada em Piracicaba, SP, a $22^{\circ} 42^{\prime}$ de latitude Sul e $47^{\circ} 38^{\prime}$ de longitude Oeste com altitude de $540 \mathrm{~m}$. Utilizou-se de uma área isolada de $5 \mathrm{~m}^{2}$, com auxílio de cerca elétrica, de um piquete de capim-elefante cv Napier em estágio de maturidade inicial de 45 dias, que eram manejados sob pastejo rotacionado com 45 dias de descanso e de um a dois dias de ocupação, com adubação de reposição de $80 \mathrm{~kg} \mathrm{ha}^{-1}$ de nitrogênio e 80 $\mathrm{kg} \mathrm{ha}^{-1}$ de $\mathrm{K}_{2} \mathrm{O}$, em Terra Roxa Estruturada com $77,3 \%$

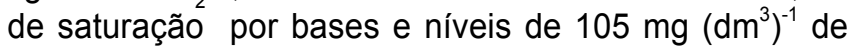
fósforo. Os cortes foram realizados, a $5 \mathrm{~cm}$ do solo em área de $1 \mathrm{~m}^{2}$, a partir dos 45 dias até 105 dias, com intervalos de 10 dias entre corte, no período de 21/04/ 95 a 21/06/95. Após a coleta, as plantas foram separadas em folhas e hastes compostas de colmos, 
bainhas e inflorescências. As amostras foram picadas manualmente e secas em estufa de circulação de ar a $60^{\circ} \mathrm{C}$ até peso constante e, posteriormente moídas a 1 $\mathrm{mm}$. Foram efetuadas, em seguida, as análises químico-bromatológicas, seguindo metodologia descrita por Goering \& Van Soest (1970) e Van Soest et al. (1991) (MSO - matéria seca original, PB - proteína bruta, FDN - fibra em detergente neutro, FDA - fibra em detergente ácido, CEL - celulose, LIG - lignina, CNE - carboidratos não estruturais, EE - extrato etéreo, MM - matéria mineral) e incubações de $100 \mathrm{mg}$ de folhas e hastes realizadas separadamente, em líquido ruminal por 48 horas de digestão, segundo metodologias descritas por Goering \& Van Soest, (1970). Adotou-se a técnica de avaliação da degradabilidade da MS pelo sistema in vitro/gás, que foi automatizada de acordo com Pell \& Schofield (1993) e avaliada por Campos (1996). Através da avaliação do resíduo remanescente da digestão estimou-se a degradabilidade da MS e da FDN adotando-se a metodologia descrita por Campos et al. (2000 a).

Adotou-se o modelo logístico bicompartimental para as avaliações dos parâmetros da cinética da digestão descritos como:

$V=\left\{A /\left[1+\operatorname{EXP}\left(2+4{ }^{*} B^{*}(C-t)\right)\right]+D /[1+E X P(2+\right.$ $\left.\left.4^{*} E^{*}(C-t)\right]\right\}$, em que $V$ é o volume total de gases $(A+D)$ em $\mathrm{mL} ; \mathrm{A}$ é o volume $(\mathrm{mL})$ de gás da degradação da fração de digestão rápida (frações solúveis e amido); B é a taxa de degradação da fração de digestão rápida (/h); C é o tempo de colonização microbiana (lag-time) em horas; $D$ é o volume $(\mathrm{mL})$ de gás da degradação da fração de digestão lenta (frações insolúveis) e E é a taxa de degradação da fração de digestão lenta $(/ \mathrm{h})$.

Foram utilizadas também das análises de regressões polinomiais para avaliar a influência da maturidade sobre a degradabilidade da MS tanto pela produção de gás como pelo resíduo da MS e FDN remanescente do processo digestivo, utilizando-se 7 níveis (idade do capim) e três repetições por amostras.

\section{RESULTADOS E DISCUSSÃO}

Durante o período de crescimento do capimelefante (45 a 105 dias) houve redução nos teores de PB tanto para folhas, hastes como para a planta inteira (folhas + hastes) e aumento acentuado dos teores de lignina, com o avanço da maturidade das hastes e da planta inteira; consequentemente menor degradabilidade da MS, avaliados tanto pela produção total de gás $(A+D)$ como pelo resíduo remanescente da digestão (método gravimétrico) (Tabelas 1 e 2). Esses resultados eram esperados, pois a lignificação tende a aumentar com a maturidade da planta. Deschamps (2001) mencionou que com a maturação fisiológica das plantas ocorrem

Tabela 1 - Valores médios da composição químico-bromatológica das frações folhas, hastes e planta inteira de capimelefante nos diferentes estágios de maturidade.

\begin{tabular}{|c|c|c|c|c|c|c|c|c|c|}
\hline Dia & $\mathrm{MSO}^{1}$ & PB & FDN & FDA & CEL & LIG & CNE & $\mathrm{EE}$ & $\mathrm{MM}$ \\
\hline \multicolumn{7}{|c|}{ Folha } & & & 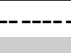 \\
\hline 45 & 19,4 & 14,3 & 71,4 & 34,5 & 31,0 & 2,5 & 1,0 & 1,2 & 12,1 \\
\hline 55 & 20,9 & 16,8 & 66,0 & 31,3 & 29,7 & 2,2 & 2,4 & 1,7 & 13,1 \\
\hline 65 & 21,9 & 14,2 & 58,5 & 30,0 & 28,0 & 2,0 & 12,7 & 2,5 & 12,0 \\
\hline 75 & 22,1 & 14,2 & 58,9 & 30,0 & 28,2 & 2,6 & 11,8 & 2,9 & 12,2 \\
\hline 85 & 23,7 & 13,5 & 58,4 & 29,1 & 26,9 & 3,2 & 11,0 & 4,1 & 13,1 \\
\hline 95 & 24,0 & 13,3 & 61,1 & 31,1 & 28,3 & 2,3 & 9,9 & 4,4 & 11,4 \\
\hline 105 & 24,0 & 12,6 & 62,0 & 30,5 & 27,8 & 2,7 & 9,8 & 4,2 & 11,5 \\
\hline \multicolumn{10}{|c|}{ Haste } \\
\hline 45 & 17,7 & 4,6 & 80,3 & 48,5 & 44,6 & 4,0 & 5,0 & 1,1 & 9,1 \\
\hline 55 & 20,3 & 4,3 & 80,0 & 50,8 & 45,7 & 5,2 & 5,1 & 2,4 & 8,2 \\
\hline 65 & 20,5 & 3,8 & 76,5 & 48,6 & 43,4 & 5,3 & 9,8 & 2,2 & 7,7 \\
\hline 75 & 24,2 & 3,6 & 75,0 & 46,7 & 41,0 & 5,6 & 12,0 & 2,2 & 7,2 \\
\hline 85 & 24,0 & 3,5 & 75,6 & 46,7 & 41,2 & 5,5 & 12,4 & 1,4 & 7,1 \\
\hline 95 & 23,0 & 3,1 & 80,4 & 48,4 & 42,5 & 5,9 & 8,3 & 1,5 & 6,7 \\
\hline 105 & 28,8 & 2,5 & 80,5 & 51,0 & 44,1 & 7,0 & 9,7 & 1,6 & 5,8 \\
\hline \multicolumn{10}{|c|}{ Folha + Haste* } \\
\hline 45 & 20,0 & 8,3 & 75,8 & 41,3 & 38,0 & 3,2 & 4,2 & 1,1 & 10,6 \\
\hline 55 & 20,5 & 9,3 & 72,8 & 41,1 & 37,4 & 3,7 & 5,3 & 1,9 & 10,7 \\
\hline 65 & 21,1 & 7,9 & 66,6 & 39,1 & 36,7 & 3,7 & 13,2 & 2,4 & 9,9 \\
\hline 75 & 23,4 & 7,8 & 66,8 & 38,3 & 35,9 & 4,8 & 13,1 & 2,6 & 9,7 \\
\hline 85 & 23,9 & 7,4 & 67,1 & 38,0 & 34,6 & 5,1 & 12,2 & 3,2 & 10,1 \\
\hline 95 & 23,4 & 7,2 & 70,3 & 38,8 & 36,6 & 4,5 & 10,2 & 3,4 & 9,0 \\
\hline 105 & 26,5 & 6,0 & 71,0 & 40,9 & 37,4 & 5,0 & 10,5 & 3,2 & 8,6 \\
\hline
\end{tabular}

${ }^{1} \mathrm{MSO}$ (matéria seca original \%); CNE (Carboidratos não estruturais); FDN (fibra em detergente neutro) - sem uso de sulfito de sódio e amilase e FDA (fibra em detergente ácido) - corrigidos para cinzas, LIG (Lignina) determinada em ácido sulfúrico a $72 \%$. PB (proteína bruta); CEL (celulose); EE (extrato etéreo) e MM (matéria mineral). *Recomposição químico-bromatológica do capim-elefante. 
modificações estruturais e químicas nos tecidos e essas refletem principalmente na redução da digestibilidade da MS. Dentre as barreiras estruturais, a cutícula e a epiderme são consideradas de grande importância devida à presença dos compostos resistentes à digestão como os n-alcanos e sílica, além da própria sinuosidade da parede celular da epiderme.

Trabalhando com capim-elefante com idades de 45 a 195 dias, Próspero (1972) constatou o aumento da parede celular de $14 \%$ para $39 \%$, redução da proteína somada ao extrato etéreo e as cinzas de $36 \%$ para $14 \%$ e redução da digestibilidade da MS in vitro de $72 \%$ para $48 \%$.

As degradabilidades da MS e da FDN de hastes apresentaram diminuição linear na taxa de desaparecimento com o avançar da maturidade (Figura 1 e Tabela 3) o que foi corroborado pela produção total de gás $(A+D)$, Figura 2 e Tabela 2. Para folhas, a degradabilidade da MS e da FDN apresentaram resultados quadráticos (Figura 1). Essas respostas estão provavelmente ligadas aos distintos componentes estruturais existentes nas hastes e nas folhas. Segundo Buxton et al. (1993) as hastes geralmente contém tecidos estruturais e condutores, enquanto folhas contém aparatos fotossintéticos localizados no interior das células do parênquima. Como resultado, hastes são menos digestível que folhas, e a digestibilidade das hastes declinam mais rapidamente com o aumento da maturidade quando comparada a folhas. Isso é condizente com resultados apresentados no presente experimento, onde a degradabilidade da MS e da FDN de folhas foram superiores $(P<0,05)$ aos de hastes, mesmo com o avançar da maturidade do capim avaliado (Tabela 3). Esses resultados corroboram os de Alves de Brito et al. (1999), que mencionou que apesar das folhas do capim-elefante também sofrerem influência da lignificação com o avanço da maturidade; estas apresentam estruturas diferenciadas como o aerênquima nas bainhas foliares, que são altamente degradadas independente da maturidade da planta. Portanto, os resultados se mostraram coerentes com os da literatura já citada; ou seja, tanto a degradabilidade da MS como a da FDN diminuíram com o avanço da maturidade da planta e provavelmente com os efeitos dos compostos fenólicos, que impedem a atuação microbiana na digestão da parede celular, caso mais acentuado nas hastes do capim-elefante (Figura 1).

Os tecidos vasculares e o esclerênquima em altas proporções são os que mais interferem na baixa taxa de degradação de partículas no rúmen. Esses tecidos e a epiderme mantêm a integridade da folha e da haste e requerem mastigação para serem rompidos. Além disso, com o tempo, as células do parênquima nas hastes de gramíneas $\mathrm{C}_{4}$ se tornam lignificadas e passam a ser uma barreira à digestão do material. É relatado também que a lignina forma ligações covalentes complexas com carboidratos da parede celular, os quais se associam com frações de hemicelulose da matriz

Tabela 2 - Estimativas dos parâmetros cinéticos da degradabilidade da matéria seca de folhas e hastes do capim-elefante, em diferentes estágios de maturidade, pela produção gás in vitro.

\begin{tabular}{|c|c|c|c|c|c|c|c|}
\hline Dia & A & $\mathrm{D}$ & $A+D$ & $\mathrm{~B}$ & $\mathrm{E}$ & $\mathrm{C}$ & $R^{2} \mathrm{C}$ \\
\hline & 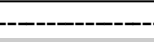 & $\mathrm{mL}$ & - & 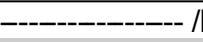 & 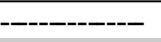 & 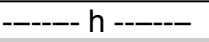 & \\
\hline \multicolumn{8}{|c|}{ Folha } \\
\hline 45 & 5,4 & 15,4 & 20,8 & 0,12 & 0,034 & 7,6 & 0,99 \\
\hline 55 & 5,5 & 12,8 & 18,3 & 0,12 & 0,036 & 6,5 & 0,99 \\
\hline 65 & 7,6 & 12,5 & 20,1 & 0,10 & 0,030 & 2,9 & 0,99 \\
\hline 75 & 13,3 & 10,0 & 23,3 & 0,10 & 0,023 & 3,4 & 0,99 \\
\hline 85 & 10,6 & 11,4 & 22,0 & 0,11 & 0,024 & 3,4 & 0,99 \\
\hline 95 & 9,8 & 13,6 & 23,4 & 0,09 & 0,024 & 3,6 & 0,99 \\
\hline 105 & 9,3 & 13,7 & 23,0 & 0,10 & 0,025 & 3,7 & 0,99 \\
\hline $\mathrm{CV}$ & 10,0 & 6,7 & 8,9 & 10,9 & 12,5 & 12,7 & \\
\hline $\mathrm{R}^{2}$ & $0,68\left(Q^{*}\right)$ & $0,80\left(Q^{*}\right)$ & $0,56\left(\mathrm{~L}^{*}\right)$ & $0,61\left(L^{*}\right)$ & $0,77\left(Q^{*}\right)$ & $0,86\left(Q^{*}\right)$ & \\
\hline \multicolumn{8}{|c|}{ Haste } \\
\hline 45 & 7,3 & 14,6 & 21,9 & 0,12 & 0,030 & 6,2 & 0,99 \\
\hline 55 & 6,1 & 13,9 & 20,0 & 0,15 & 0,032 & 7,2 & 0,99 \\
\hline 65 & 10,0 & 7,7 & 17,7 & 0,06 & 0,050 & 3,9 & 0,99 \\
\hline 75 & 12,0 & 3,7 & 15,7 & 0,03 & 0,095 & 2,9 & 0,99 \\
\hline 85 & 2,6 & 10,9 & 13,5 & 0,12 & 0,024 & 2,4 & 0,99 \\
\hline 95 & 2,6 & 10,4 & 13,0 & 0,16 & 0,029 & 4,6 & 0,99 \\
\hline 105 & 2,5 & 10,7 & 3,2 & 0,18 & 0,024 & 6,1 & 0,94 \\
\hline$\overline{\mathrm{CV}}$ & 26,4 & 21,7 & 21,6 & 27,7 & 32,4 & 34,33 & \\
\hline$R^{2}$ & $0,51\left(Q^{*}\right)$ & $0,56\left(Q^{*}\right)$ & $0,92\left(L^{*}\right)$ & $0,60\left(L^{*}\right)$ & $0,35\left(Q^{*}\right)$ & $0,67\left(Q^{*}\right)$ & \\
\hline
\end{tabular}

$\mathrm{V}$ - volume total de gases (A+D); $\mathrm{A}$ - $\mathrm{mL}$ de gás da fração de digestão rápida (frações solúveis e amido); $\mathrm{B}$ - taxa de degradação da fração de digestão rápida; C - tempo de colonização (lag-time); $D$ - $\mathrm{mL}$ de gás da fração de digestão lenta (frações insolúveis); $E$ - taxa de degradação da fração de digestão lenta; $R^{2} \mathrm{C}$ - coeficiente de determinação da estimativa dos parâmetros cinéticos da digestão.

$\mathrm{CV}=$ coeficiente de variação $(\%) ; \mathrm{R}^{2}=$ coeficiente de determinação das análises de regressões

$Q^{*}=$ Regressão quadrática significativa $(P<0,05)$

$L^{*}=$ Regressão linear significativa $(P<0,05)$ 
Tabela 3 - Estimativa da degradabilidade da matéria seca (MS) e da fibra em detergente neutro (FDN) de folhas e hastes do capim-elefante, em diferentes estágios de maturidade, pelo resíduo remanescente da digestão in vitro/gás.

\begin{tabular}{lcc}
\hline Dia & Degradabilidade da MS & Degradabilidade da FDN \\
\hline & & \\
Folha & 81,3 & 71,6 \\
45 & 79,4 & 66,4 \\
55 & 78,3 & 60,3 \\
65 & 80,4 & 64,2 \\
75 & 77,5 & 58,8 \\
85 & 77,2 & 60,3 \\
95 & 79,3 & 64,2 \\
105 & 5,8 & 8,6 \\
\hline CV & $0,51\left(\mathrm{QL}^{\mathrm{NS}}\right)$ & $0,82\left(\mathrm{Q}^{*}\right)$ \\
\hline $\mathrm{R}^{2}$ & & \\
\hline $\mathrm{Haste}$ & 70,4 & 61,1 \\
45 & 66,1 & 55,6 \\
55 & 60,8 & 46,7 \\
65 & 61,7 & 47,0 \\
75 & 60,1 & 45,2 \\
85 & 54,1 & 41,7 \\
95 & 45,7 & 32,5 \\
\hline 105 & 4,2 & 4,3 \\
\hline $\mathrm{CV}$ & $0,89\left(\mathrm{~L}^{*}\right)$ & $0,92\left(\mathrm{~L}^{*}\right)$ \\
\hline $\mathrm{R}^{2}$ & &
\end{tabular}

$C V$ = coeficiente de variação; $R^{2}=$ coeficiente de determinação das regressões

$Q^{*}=$ Regressão quadrática significativa $(P<0,05)$

$L^{*}=$ Regressão linear significativa $(P<0,05)$

ns $=$ não significativo $(P>0,05)$
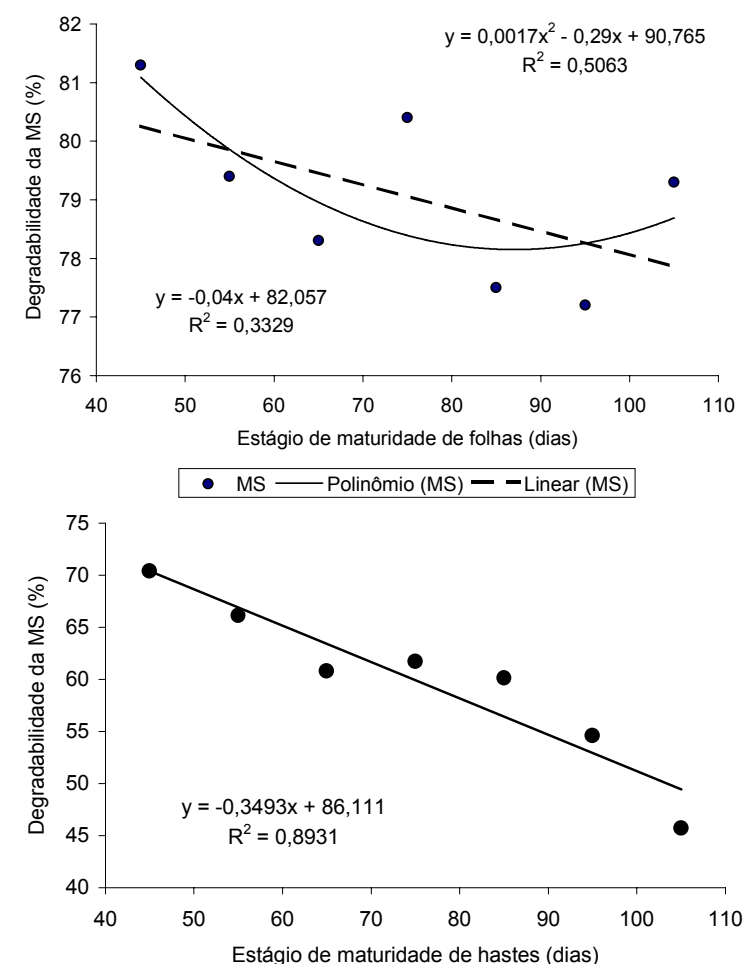

(Thiago \& Gill, 1990). Portanto, a digestibilidade da parede celular é influenciada tanto pelo teor como também pelas características físicas dos polissacarídeos da parede celular como o grau de cristalinidade e polimerização (Cowling, 1975 citado por Fritz et al., 1990). Assim, a lignina cria uma barreira física à ação dos microrganismos fermentadores, cujos maiores teores são observados na época de florescimento. Nascimento Junior \& Pinheiro (1975) determinaram que para o aumento de cada unidade percentual no teor de fibra do capim jaraguá (Hyparrhenia rufa (Ness) Stapf.), ocorria queda de 3,4 unidades percentuais na digestibilidade da MS; e que a lignina foi mais responsável que os demais componentes da fibra por esse decréscimo na digestibilidade.

Uma das características químicas da lignina é a relação ácido cumárico: ferúlico que tem sido correlacionada positivamente com a digestão in vitro (Jung et al., 1991) por ocorrer ligação mais estável da lignina com polissacarídeos através do ácido cumárico do que com o ferúlico (Fritz, et al., 1990). A relação entre o ácido cumárico e o ferúlico é diferente para hastes e folhas: nas hastes, essa relação é sempre maior, o que pode explicar a redução na digestibilidade destas. A menor digestibilidade da haste em relação às folhas também pode ser explicada pela maior relação xilose:arabinose da hemicelulose das folhas. Esse fato pode estar associado à maior taxa de degradação das folhas em relação às hastes (Akin \& Rigsby, 1991). Segundo McNeil et al. (1975) citado por Fritz et al. (1990), a arabinose forma ligações mais estáveis com a lignina do que com a xilose.
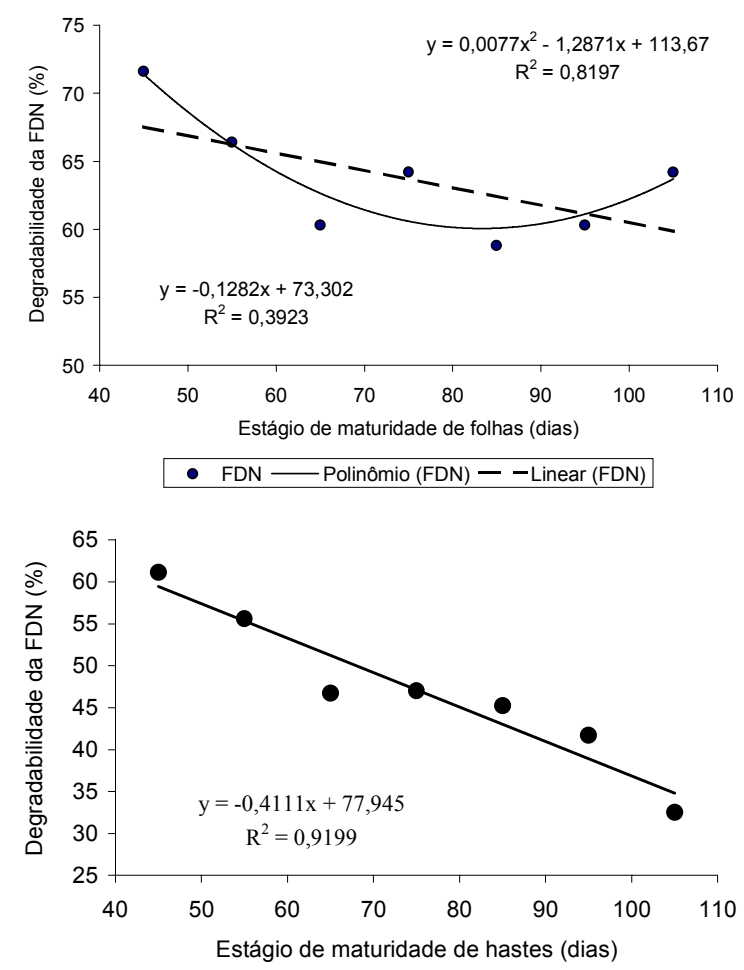

Figura 1 - Análises de regressão da degradabilidade da matéria seca (MS) e da fibra em detergente (FDN). 
A proporção percentual média de hastes e folhas, em termos de peso total de matéria seca colhida no período total, no presente experimento, foi de 36,0 $\%$ para folhas e $64,0 \%$ para hastes (proporção percentual entre hastes: folhas nos diferentes estágios de maturidade, 45 a 105 dias: $71,5: 28,5 ; 65,7: 34,3$; $60,5: 39,5 ; 61,4: 38,6 ; 60,3: 39,7 ; 62,3: 37,7 ; 66,1: 33,9$, respectivamente. Os resultados apresentados na Figura 3 , para as relações haste: folha do capim-elefante, foram obtidas a partir do peso médio da matéria seca colhida em cada período. Notou-se efeito quadrático para a relação haste:folha com o avançar da idade do capim. Isso pode estar relacionado ao aparecimento de perfilhos novos ou pela elongação das folhas, que provavelmente possuíam hastes com peso superior aos de folhas, o que ocasionou a redução na relação verificada até aos 75 dias. Aos 45 dias a relação haste:folha foi de 2,5 , ou seja, as hastes apresentaram peso de 2,5 vezes superiores

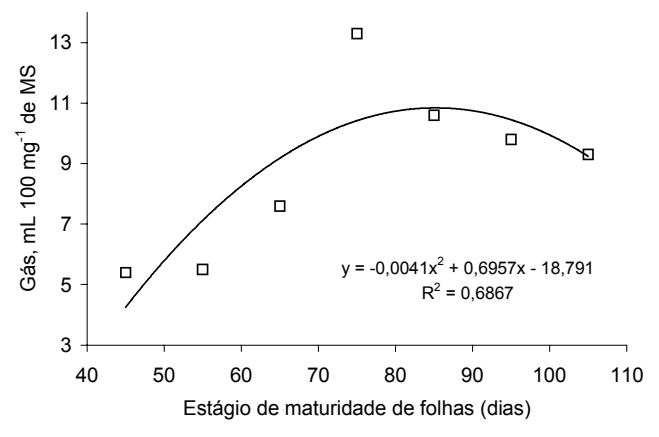

口 A Polinômio (A)

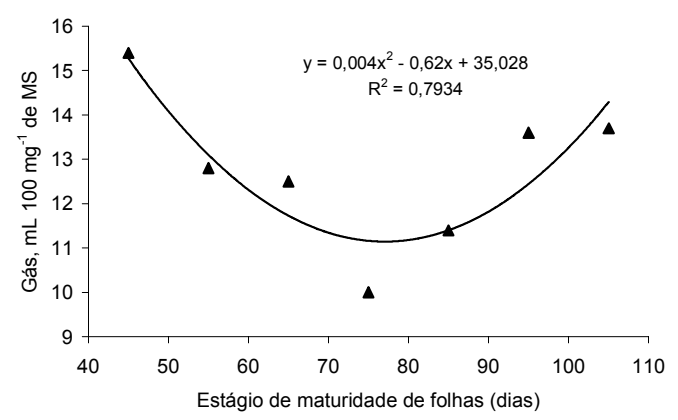

$\Delta \quad \mathrm{D} \quad$ Polinômio (D)

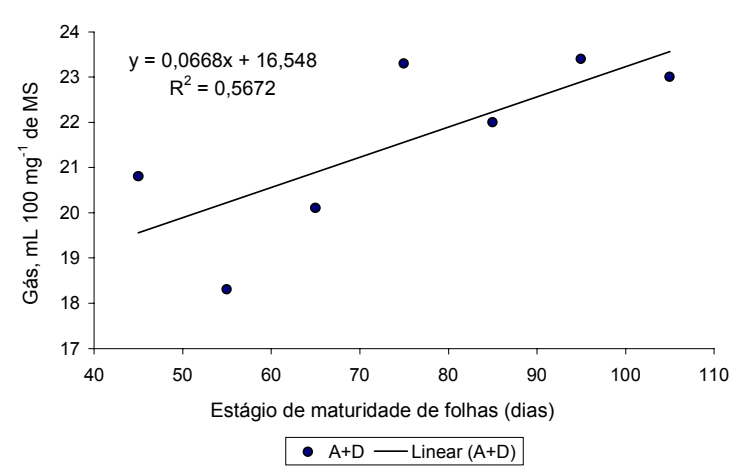

aos de folhas, porém o valor qualitativo apresentado pelas hastes, aos 45 dias, foram consideráveis quando comparadas aos de 105 dias (Tabelas 2 e 3). É evidente que a idade do capim foi o fator mais preponderante nas avaliações e interferiram decisivamente no valor nutritivo do capim-elefante, resultado condizente com o encontrado por Campos (2000 b), que avaliou a degradabilidade da matéria seca de Capim-elefante cv. Taiwan com duas maturidade, de 60 e 180 dias, pelo método de produção de gás. Houve queda acentuada nos valores de produção de gás de $16,9 \mathrm{~mL}$ para 11,7 $\mathrm{mL}$, e reduções na degradabilidade da MS de $61,5 \%$ para $34,6 \%$ e da FDN de $53,9 \%$ para $35,4 \%$, respectivamente, para o capim de 60 e 180 dias. Portanto, a proporção haste:folha é um valor relativo à produção de matéria seca e não define um valor nutritivo e sim uma estimativa relativa dos componentes da planta. Sua importância está mais relacionada ao
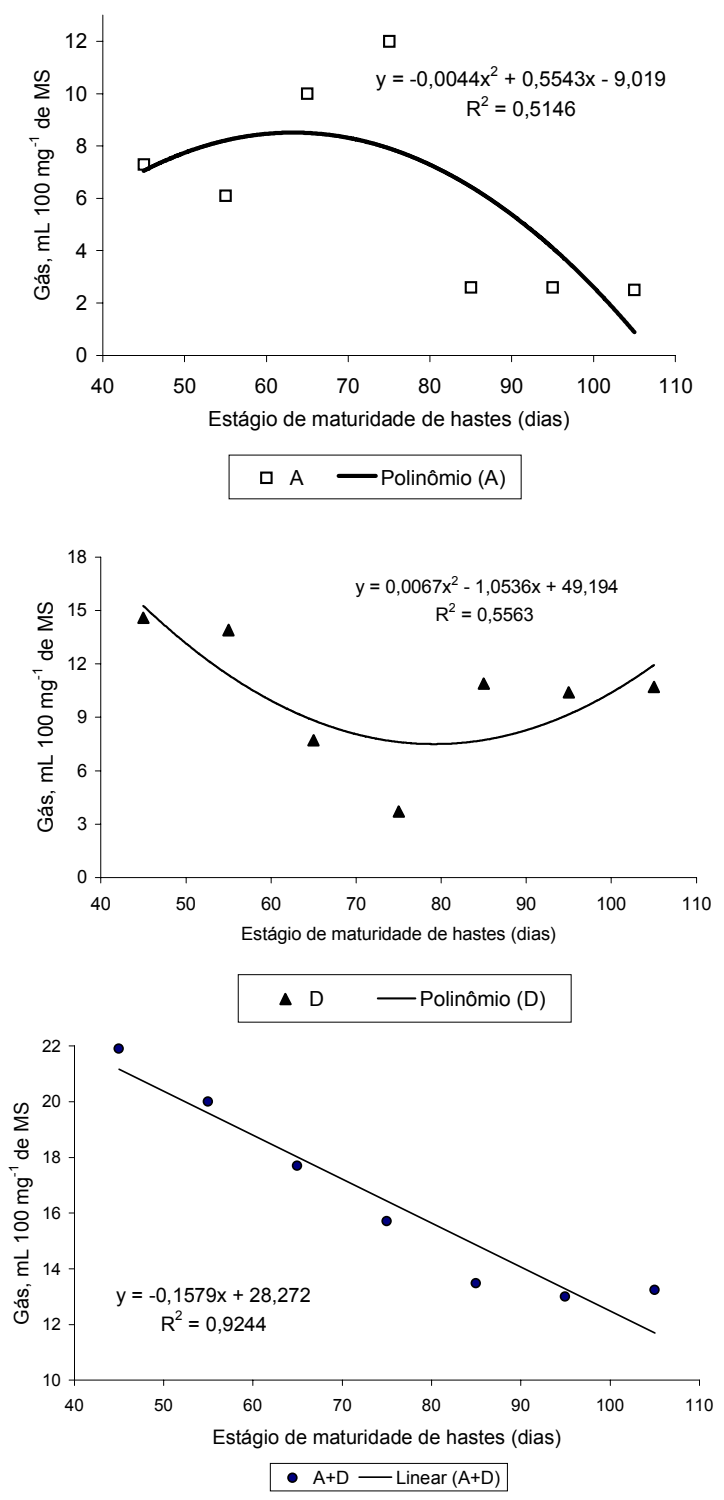

Figura 2 - Análises de regressão da degradabilidade da matéria seca (MS) de folhas e hastes do capim-elefante em diferentes estágios de maturidade $(A=$ volume de gás da fração solúvel e amido; $D$ = volume de gás da fração insolúvel; $A+D=$ volume total de gás). 


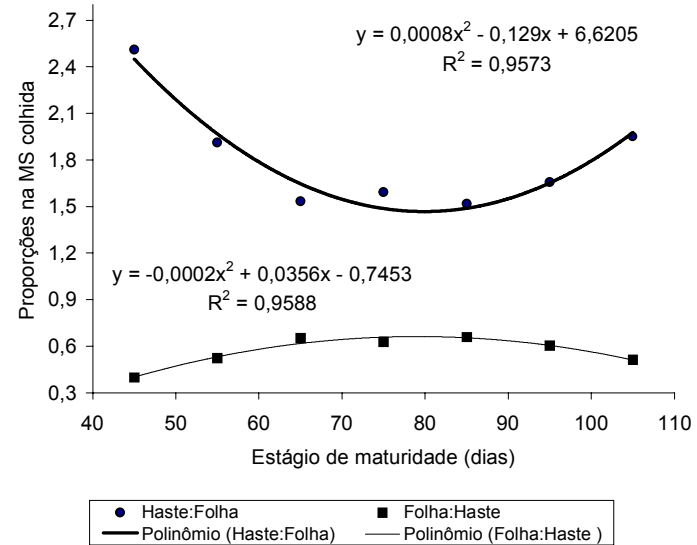

Figura 3 - Análises de regressão das relações haste:folha e folha: haste, em termos de peso total da matéria seca colhida nos diferentes estágios de maturidade do capim-elefante.

manejo do capim, no caso o capim-elefante cv Napier. Tendo em vista que as diferenças físicas e químicas existentes, entre e hastes e folhas, são dependentes de vários fatores como idade do capim, tipo de cultivar, aparecimento de perfilhos laterais, da intensidade luminosa, do clima, da pluviosidade, da fertilidade do solo, etc. Entretanto, esta relação poderá se utilizada na nutrição animal como um fator de estimativa de consumo de forragem, o que está de acordo com Galyean \& Goetsch (1993) que mencionaram que a relação folha:haste de forragens afetam diretamente o nível de ingestão de alimento, embora mudanças na digestão resultante dessa proporção não são previsíveis. Foi relatado também, que o consumo somente de folhas é maior que haste, devido ambos possuírem características distintas nos tempos de retenção ruminal, resultando em modificações na ingestão de alimento, assim folhas passam mais rapidamente no rúmen do que hastes.

No presente trabalho notou-se aumento linear no teor de carboidratos não estruturais (CNE) com o avanço da maturidade de folhas e de hastes do capimelefante (Tabela 1); porém, a produção de gás apresentada pelo parâmetro de digestão rápida $(A)$ de folhas e hastes do capim-elefante não acompanhou linearmente os teores de carboidratos solúveis apresentados e, sim de forma quadrática, conforme mostrado no parâmetro A da Figura 2. Provavelmente houve efeito dos compostos fenólicos que impediram a ação dos microrganismos fermentadores da parede celular. Segundo Deschamps (2001) a maturação fisiológica do vegetal promove a formação de complexos de elevado peso molecular, os quais envolvem a hemicelulose e a celulose. Esses complexos, associando-se à hemicelulose, impedem a atuação de enzimas na degradação dos carboidratos. Outros estudos realizados por Akin (1988) demonstraram que os compostos fenólicos inibem a aderência e a digestão da fibra por culturas puras ou mistas de microrganismos ruminais. Mesmo assim, observou-se a contribuição da produção de gás da fração solúvel $(A)$ na extensão da degradação $(A+D)$ das folhas do capim-elefante de 45 a 105 dias e efeito reduzido do volume de gás do parâmetro $A$ na produção total de gás observada no parâmetro $A+D$, nas faixas de 85 a 105 dias para as hastes do capim-elefante (Tabela 2).

A produção de gás da fração de digestão lenta (D) para folhas permaneceu constante, com exceção das folhas com 45 dias, cuja produção foi superior aos demais tratamentos. Porém, o volume de gás do parâmetro $D$ apresentou respostas quadráticas (Figura 2) com o avanço da maturidade de hastes e folhas. Esses resultados quadráticos poderiam ser explicados pelo aparecimento de novos perfilhos que antecederam os cortes, cresceram com idades diferenciadas e resultando em aumento na produção de gás da fração fibrosa (D) observados nos períodos de 85 a 105 dias (Figura 2). Com relação às taxas de degradação da fração de digestão rápida $(B)$ e lenta $(E)$ não houve um padrão uniforme com o avanço da maturidade do capim. Resultados semelhantes foram observados por Lanna et al. (1996) em avaliações de folhas e hastes de capim-elefante, com 45 dias, analisados em diferentes épocas de colheitas: outubro, janeiro ou abril.

Analisando os resultados da taxa de degradação da fração de digestão lenta $(E)$ constatouse respostas quadráticas $(P<0,05)$ com o avançar da idade das folhas $\left(R^{2}=0,77\right)$ e das hastes $\left(R^{2}=0,35\right)$. As respostas foram diferentes do que se esperava, linear e negativa com o avançar da idade. A provável explicação para isso pode estar ligada ao aparecimento de novos perfilhos no período de 65 a 75 dias que interferiram nas respostas (Tabela 2). Esse efeito foi nítido no parâmetro $\mathrm{A}$, para hastes nos períodos de 65 e 75 dias, que foram superiores aos demais. Provavelmente isso ocorreu por efeito dos teores de carboidratos não estruturais destes perfilhos novos que favoreceram o crescimento de bactérias não celulolíticas, o que deprimiu a produção de gás da fração fibrosa (D). O provável aparecimento de perfilhos é visualizado na Figura 2, no parâmetro $A$ para hastes e folhas, nas idades de 65 e 75 dias. Entretanto, o efeito da maturidade sobre as taxas de degradação das frações de digestão lenta $(E)$ das folhas e das hastes com 45 dias comparadas às de 105 dias foram nitidamente visualizadas pelas variações apresentadas, $36 \%$ para folhas e $25 \%$ para hastes (Tabela 2). Podese inferir que uma taxa de degradação mais lenta refletirá em maior tempo de retenção da fração fibrosa no rúmen e consequentemente diminuirá o consumo e o desempenho produtivo dos ruminantes.

Quanto ao "lag time" (C) os valores médios foram elevados e superiores aos encontrados para gramíneas. Para folhas e hastes foram notados maiores tempos de colonização para os capins com 45 e 55 dias 
de maturidade. Isso pode estar ligado ao efeito de diluição dos carboidratos não estruturais, que apesar de apresentarem menores teores, mostraramse mais disponíveis para a atuação microbiana; consequentemente, há maior competição por este substrato, o que pode ter afetado inicialmente o tempo de colonização da parede celular pelas bactérias celulolíticas (Tabela 2).

Em geral, a produção total de gás $(A+D)$ proveniente da digestão de folhas aumentou linearmente com o avanço da maturidade vegetal, porém, com baixo coeficiente de determinação $(0,56)$. Para as hastes houve decréscimo acentuado no parâmetro $A+D$ com o avanço da maturidade e com elevado coeficiente de determinação $(0,90)$ (Tabela 2 e Figura 2).

Constatou-se também acúmulo de carboidratos não estruturais com o aumento da maturidade do capim (Tabela 1), embora esse aumento não tenha refletido na maior produção de gás, como pode ser observado no parâmetro $\mathrm{A}$. Isso provavelmente se deve à ação dos compostos químicos que impedem o rompimento da parede celular para que ocorra o extravasamento dos componentes do conteúdo celular. Tal fato pode ser visualizado na Tabela 2, parâmetro $A$, para hastes com 85 a 105 dias de maturidade. Nesse estágio houve menor contribuição na produção total de gás $(A+D)$ no processo digestivo dessas plantas. Portanto, tanto para folhas como para hastes do capimelefante as respostas foram similares na produção de gás e no resíduo remanescente da digestão. As duas formas de avaliação detectaram que a degradação da MS e/ou da FDN das hastes foi mais afetada pela maturidade do capim-elefante (Tabelas 2 e 3; Figuras 1 e 2).

Em geral, a fração haste do capim-elefante influenciou mais a degradabilidade da MS que as folhas com o avanço da maturidade vegetal. Isso está ligado à constituição anatômica diferenciada de folhas e hastes. Segundo Alves de Brito (1997) a disposição dos tecidos no colmo de capim-elefante é bastante diferenciada do arranjo apresentado nas folhas, o que permite concluir que somente o conteúdo de lignina não é suficiente para explicar a redução na digestão dos tecidos do colmo desta forrageira. Alves de Brito et al. (1999) mencionaram também que a quilha e o colmo de capimelefante foram estruturas onde as áreas de tecidos lignificados estavam mais presentes. No colmo, a área de lignificação pode ser associada à presença da bainha esclerenquimática que circunda os feixes vasculares. Notaram também que a bainha foliar apresentou menor quantidade de tecido parenquimático e isso foi atribuído em parte à formação do aerênquima no mesófilo. Essa estrutura, que possui a finalidade de proporcionar ambiente favorável à troca de gases, contribui ao facilitar a degradação da bainha, ao formar lacunas originadas pelo rompimento de células de parênquima e que favorecem a movimentação dos microrganismos no interior do mesófilo (Alves de Brito et al., 1999), facilitando assim a disseminação dos microrganismos ruminais.

Foram constatados, também, por Alves de Brito et al. (1999) que os estômatos presentes na epiderme de bainhas e lâminas foram utilizados pelos microrganismos como via de acesso aos tecidos mais internos, iniciando-se assim o processo de degradação dos tecidos. Portanto, os autores concluíram que a área ocupada pelo tecido lignificado aumentou com o crescimento das plantas, tanto nas folhas quanto no colmo, e a degradação dos tecidos presentes nas diferentes estruturas diminuiu com a idade da planta, com exceção da bainha foliar, que em razão da presença do aerênquima, apresentou sua área de degradação aumentada.

No presente experimento observou-se que tanto a degradabilidade da MS como da FDN de folhas não apresentaram variações em função de maturidade e, provavelmente isso esteja ligado à presença de estruturas como o aerênquima, que não promove diferenciação na digestão das folhas do capim-elefante com avançar da idade da planta.

Estudo realizados por Deschamps (1999) mostraram que a maturidade dos tecidos está correlacionada diferentemente com o incremento nas concentrações de FDN e lignina e inversamente com a digestibilidade da MS e FDN. Foi observado que a lignificação influencia a digestão do colmo mais drasticamente que a digestão das folhas. Resultados semelhantes foram encontrados no presente experimento, onde se constatou que a variação da degradabilidade da MS das hastes foi reduzido de $70,4 \%$ para $45,7 \%$ e a degradabilidade da FDN de $61,1 \%$ para $32,5 \%$, com a variação da maturidade do capim de 45 a 105 dias (Tabela 3). Portanto, a importância de manejar corretamente o pastejo influenciará diretamente no desempenho produtivo de bovinos consumidores deste tipo de forragem. Resultados que estão de acordo com relatos de Van Soest (1994), o qual mencionou que à medida que aumenta a idade das plantas são verificados o maior grau de lignificação e menor acessibilidade microbiana, resultando em maior resíduo indigestível, o que pode limitar o consumo de MS através do efeito de enchimento do tratogastrointestinal dos ruminantes.

\section{CONCLUSÕES}

O avanço do estágio de maturidade da planta afeta diretamente a degradabilidade da matéria seca e da fibra em detergente neutro das frações hastes e folhas do capim-elefante, sendo mais acentuado para hastes pela maior lignificação da parede celular.

\section{AGRADECIMENTO}

À Fundação de Amparo à Pesquisa do Estado de São Paulo - FAPESP pelo financiamento do projeto. 


\section{REFERÊNCIAS BIBLIOGRÁFICAS}

AKIN, D.E. Biological structure of lignocellulose and its degradation in the rumen. Animal Feed Science and Technology, v.21, p.295-310, 1988.

AKIN, D.E.; RIGSBY, L. Structure and digestibility of tissues in normal and brown midrib pearl millet (Pennisetum glaucum). Journal of the Science of Food and Agriculture, v.56, p.523-538, 1991.

ALVES DE BRITO, C.J.F. Organização estrutural e degradação in vitro de tecidos em Pennisetum purpureum Schum. (Poaceae). Curitiba, 1997. 119p. Dissertação (Mestrado) - Universidade Federal do Paraná

ALVES DE BRITO, C.J.F.; RODELLA, R.A.; DESCHAMPS, F.C.; ALQUINI, Y. Anatomia quantitativa e degradação in vitro de tecidos em cultivares de capim-elefante (Pennisetum purpureum Schumach.). Revista Brasileira de Zootecnia, v.28, p.223-229, 1999.

BALSALOBRE, M.A.A. Desempenho de vacas em lactação sobre pastejo rotacionado de capim-elefante (Pennisetum purpureum, Schum.) Piracicaba, 1996. 139p. Dissertação (Mestrado) - Escola Superior de Agricultura "Luiz de Queiroz", Universidade de São Paulo.

BUXTON, D.R.; CASLER, M.D. Environmental and genetic effects on cell walls. In: JUNG, H.G.; BUXTON, D.R.; HATFIELD, R.D.; RALPH, J. (Ed.) Forage cell wall structure and digestibility. Madison: ASA; CSSA; SSSA, 1993. p.685-714.

CAMPOS, F.P. Avaliação do sistema de monitoramento computadorizado de digestão in vitro e produção de gás comparada com os métodos in vivo e in situ. Piracicaba, 1996. 61p. Dissertação (Mestrado) - Escola Superior de Agricultura "Luiz de Queiroz", Universidade de São Paulo.

CAMPOS, F.P.; LANNA, D.P.D.; BOSE, M.L.V.; BOIN, C. Avaliação do sistema de monitoramento computadorizado de digestão in vitro: 1. Testes preliminares. Revista Brasileira de Zootecnia, v.29, p.525-530, 2000a.

CAMPOS, F.P. Digestibilidade de alguns volumosos através do monitoramento computadorizado de produção de gás in vitro. Jaboticabal, 2000b. 111p. Tese (Doutorado) - Faculdade de Ciências Agrárias e Veterinárias, Universidade Estadual Paulista "Júlio de Mesquita Filho".

DESCHAMPS, F.C. Implicações do período de crescimento na composição química e digestão dos tecidos de cultivares de capim-elefante (Pennisetum purpureum Schumach.). Revista Brasileira de Zootecnia, v.28, p.1358-1369, 1999.

DESCHAMPS, F.C. Qualidade da forragem e participação relativa na produção de matéria seca de diferentes frações de cultivares de capimelefante(Pennisetum purpureum Schumach.). Revista Brasileira de Zootecnia, v.30, p.1418-1423, 2001.

FRITZ, J.O.; MOORE, K.J.; JASTER, E.H. Digestion kinetics and cell wall composition of brown midrib sorghum $\mathrm{x}$ sudan grass morphological components. Crop Science, v.30, p.213-219, 1990.
GALYEAN, M.L.; GOETSCH, A.L. Utilization of forage fiber by ruminants. In: JUNG, H.G.; BUXTON, D.R.; HATFIELD, R.D.; RALPH, J. (Ed.) Forage cell wall structure and digestibility. Madison: ASA, CSSA, SSSA, 1993. p.33-71.

GOERING, K.H.; VAN SOEST, P.J. Forage fiber analysis: apparatus, reagents, procedures, and some application. Washington: USDA, 1970. $379 p$.

JUNG, H.G.; RALPH, J.; HATFIELD, R.D. Degradability of phenolic acidhemicellulose esters a model system. Journal of the Science of Food and Agriculture, v.56, p.469-478, 1991.

LANNA, D.P.D.; FOX, D.G.; BALSALOBRE, M.A.A.; CORSI, M.; TRAXLER, M. Utilização da metodologia de análises de alimentos do CNCPS e do sistema de produção de gás in vitro na estimativa do valor nutricional do capim-elefante. In: REUNIÃO ANUAL DA SOCIEDADE BRASILEIRA DE ZOOTECNIA, 33., Fortaleza, 1996. Anais. Fortaleza: SBZ, 1996. p.289291.

LAREDO, M.A.; MINSON, D.J. The voluntary intake, digestibility, and retention the time by sheep of leaf and stem fractions of five grasses. Australian Journal of Agricultural Research, v.24, p.875-878, 1973.

NASCIMENTO JR., D.; PINHEIRO, J.S. Valor nutritivo do capim-jaraguá em diferentes idades. Revista da Sociedade Brasileira de Zootecnia, v.41, p.101-103, 1975.

PELL, A.N. SCHOFIELD, P. Computerized monitoring of gas production to measure forage digestion in vitro. Journal of Dairy Science, v.76, p.10631073, 1993.

PROSPERO, A.O. Variação estacional da composição química-bromatológica do teor de macronutrientes minerais e da digestibilidade in vitro do capimelefante (Pennisetum purpureum Schum). Variedade Napier. Anais da ESALQ, v.29, p.81-83, 1972.

THIAGO, L.R.L.S.; GILL, M. Consumo voluntário de forragem por ruminantes: mecanismo físico ou fisiológico. Revista da Sociedade Brasileira de Zootecnia, v.19, p.47-78, 1990

ULYATT, M.J.; DELLOW, A.J.; JOHN, A.; REID, C.S.W.; WAGHORN, G.C. Contribution of chewing during eating and ruminant to the clearance of digest from the ruminoreticullum. In: MILLIGAN, L.P.; GROVUM, W.L.; DOBSON, A. (Ed.) Control of digestion and metabolism in the ruminants. Boston: Reston Publishing, 1986. p.498-515.

VAN SOEST, P.J.; ROBERTSON, J.B.; LEWIS, B.A. Methods for dietary fiber neutral detergente fiber, and nonstarch polysaccharides in relation to animal nutrition. Journal of Dairy Science, v.74, p.3583-3597, 1991.

VAN SOEST, P.J. Nutritional ecology of the ruminant. 2.ed. Ithaca: Cornell University Press, 1994. 476p

Recebido em 29.01.01 